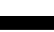

\title{
Isoflurane Preconditioning Increases Survival of Rat Skin Random-Pattern Flaps by Induction of HIF-1 $\alpha$ Expression
}

\author{
Yu Sun Qi-Fang Li Ying Zhang Rong Hu Hong Jiang \\ Department of Anesthesiology, Shanghai Ninth People's Hospital Affiliated to Shanghai Jiao Tong \\ University, School of Medicine, Shanghai
}

\section{Key Words}

Random-pattern skin flap • Isoflurane $•$ Hypoxia inducible factor $1 \alpha \cdot$ Akt-mTOR • Akt-GSK $3 \beta$

\begin{abstract}
Background: Survival of random-pattern skin flaps is important for the success of plastic and reconstructive surgeries. This study investigates isoflurane-induced protection against ischemia of skin flap and the underlying molecular mechanism in this process. Methods: Human umbilical vein endothelial cells (HUVECs) and human skin fibroblast cells were exposed to isoflurane for $4 \mathrm{~h}$. Expression of hypoxia inducible factor- $1 \alpha$ (HIF-1 $\alpha$ ), heme oxygenase- 1 $(\mathrm{HO}-1)$ and vascular endothelial growth factor (VEGF) were analyzed up to $24 \mathrm{~h}$ post isoflurane exposure using qRT-PCR and western blot, or ELISA analyses. PI3K inhibitors - LY 294002 and wortmannin, mTOR inhibitor - rapamycin, and GSK3 $\beta$ inhibitor - SB 216763 were used respectively to assess the effects of isoflurane treatment and HIF-1 $\alpha$ expression. Furthermore, 40 rats were randomly divided into 5 groups (control, isoflurane, scrambled siRNA plus isoflurane, HIF- $1 \alpha$ siRNA plus isoflurane, and DMOG) and subjected to random-pattern skin flaps operation. Rats were prepared for evaluation of flap survival and full-field laser perfusion imager (FLPI) (at 7 day) and microvessel density evaluation (at 10 day). Results: Isoflurane exposure induced expression of HIF-1 $\alpha$ protein, HO-1 and VEGF mRNA and proteins in a time-dependent manner. Both LY 294002 and wortmannin inhibited phospho-Akt, phosphomTOR, phospho-GSK $3 \beta$ and HIF-1 $\alpha$ expression after isoflurane exposure. Both wortmannin and rapamycin inhibited isoflurane-induced phospho-4E-BP1 (Ser 65) and phospho-P70 $56 \mathrm{k}$ (Thr 389) and HIF-1 $\alpha$ expression. SB 216763 pre-treatment could further enhance isofluraneinduced expression of phospho-GSK $3 \beta$ (Ser 9) and HIF-1 $\alpha$ protein compared to the isofluranealone cells. In animal experiments, isoflurane alone, scrambled siRNA plus isoflurane, or DMOG groups had significantly upregulated vascularity and increased survival of the skin flaps compared to the controls. However, HIF-1 $\alpha$ knockdown abrogated the protective effect of isoflurane preconditioning in rats. Conclusions: Isoflurane preconditioning improves survival of skin flaps by up the regulation of HIF-1 $\alpha$ expression via Akt-mTOR and Akt-GSK $3 \beta$ signaling pathways.




\section{Introduction}

Random-pattern tissue flaps are frequently used in plastic and reconstructive surgery to cover soft tissue defects that may have been caused due to trauma or tumor-resection. Necrosis of the ischemic portion of the random-pattern skin flap is one of the common complications observed during these tissue transfer procedures. This unexpected tissue loss could result in significant cosmetic and functional defects [1]. The reason for such necrosis could either be due to loss or limited blood supply to the tissue flaps and the underlying molecular mechanisms of this process remain to be defined. Thus, many approaches, such as using unspecific local or systemic physical stressors, pharmacological agents, or even treating the flap with different growth factors, have been explored to reduce distal flap necrosis. However, most of these techniques require invasive and expensive administration of these substances. Therefore, novel approaches are needed to prevent such skin tissue necrosis and improve the success of the plastic and reconstructive surgical procedure.

Towards this end, our research focuses on a transcription factor, hypoxia inducible factor 1 (HIF-1). Its role in cellular response to ischemia has been extensively investigated in numerous studies. HIF-1 is composed of two basic helix-loop-helix proteins subunits, $\alpha$ and $\beta$. HIF- $1 \alpha$, plays an essential role in triggering cellular protection and metabolic alterations in response to oxygen deprivation [2,3]. Angiogenesis is an important factor for the survival of random-pattern skin flap [4]. HIF-1 $\alpha$ is known to regulate angiogenesis and microcirculation through mediators, such as vascular endothelial growth factor (VEGF) [5] and heme oxygenase (HO)-1 [6]. Thus, indicating the role of HIF-1 $\alpha$ expression in the survival of random-pattern skin flaps. Recently, several studies have confirmed this role by demonstrating that intraperitoneal treatment with a HIF-1 $\alpha$ stabilizer dimethyloxalylglycine (DMOG) or deferoxamine (DFO), significantly increased HIF-1 $\alpha$ expression and enhanced skin flap survival [7-10].

Isoflurane, 2-chloro-2-(difluoromethoxy)-1,1,1-trifluoro-ethane, is halogenated ether used for clinical inhalational anesthesia. We and others have demonstrated that isoflurane was able to modulate expression of several genes related to cell survival, including HIF-1 $\alpha$ [11-15]. Tissue preconditioning properties of isoflurane have been well described in the literature and are established in clinical practice [14, 16-19]. Therefore, we hypothesized that isoflurane preconditioning might be beneficial in reducing necrosis in ischemic skin flaps through up-regulation of HIF- $1 \alpha$ and its downstream genes.

In this study, we performed in vitro and in vivo experiments to test whether isoflurane preconditioning could induce tolerance against hypoxia/ischemia in skin flap tissues. In addition, we also elucidated the underlying molecular events to confirm the role of HIF-1 $\alpha$ in this process.

\section{Materials and Methods}

\section{Cell lines and animals}

Human umbilical vein endothelial cells (HUVECs) and human skin fibroblast cells were purchased from the Cell Bank of Shanghai Institute for Biological Science (Shanghai, China). These cell lines were seeded at $1 \times 10^{3}$ per $\mathrm{cm}^{2}$ on tissue culture plates. Twenty-four hours later, non-adherent cells were washed off using phosphate buffered saline (PBS). The adherent cells were grown to confluency. Cells from passages 3 or 4 were used in the following experiments.

Adult male Sprague-Dawley rats (weighing $300 \pm 20$ g) were obtained from SLAC National Rodent Laboratory Animal Resource (Shanghai, China). Rats were housed in temperature- and humidity-controlled, specific pathogen-free (SPF) conditions on a $12 \mathrm{~h}$ light/12 h dark cycle with free access to food and water. Animal study was in accordance with the National Institutes of Guide for Care and Use of Laboratory Animals (NIH US publication 86-23, revised 1985) and approved by the Committee of Animal Experimental Ethical Inspection Shanghai Ninth People's Hospital affiliated to Shanghai Jiao Tong University, School of Medicine. 
Sun/Li/Zhang/Hu/Jiang: Isoflurane Improves Skin Flap Survival

\section{Isoflurane exposure}

Cells were incubated in vitro with isoflurane (Abbott Laboratories, Abbott Park, IL) for $4 \mathrm{~h}$ in a gastight chamber inside the culture incubator as described previously [20,21]. Isoflurane concentrations used in vitro assays were $0.16,0.32$ and $0.48 \mathrm{mM}$, equivalent to $0.5,1.0$ and 1.5 minimum alveolar concentrations (MAC), respectively.

Animals were exposed to isoflurane as described previously [18]. Briefly, a homemade tilt transparent plastic chamber with in- and out-flow at the opposite long ends was used. Rats were exposed to $1.5 \%$ isoflurane (equivalent to 1.0 MAC for rats) balanced with air through an isoflurane vaporizer for $4 \mathrm{~h}$ period of time, while the control animals were exposed to the same gas without isoflurane. Gas sample was taken from a hole adjacent to the outlet for measurement. Concentrations of isoflurane and $\mathrm{O}_{2}$ were monitored by Datex infrared analyzer (Capnomac, Helsinki, Finland). The concentration of isoflurane inhalation used in this study was a common clinical concentration that did not cause any cardiorespiratory compromise in our pilot studies.

To determine whether isoflurane exposure activates HIF-1 $\alpha$ in HUVECs and human skin fibroblast cells, we exposed these cells to $0.32 \mathrm{mM}$ isoflurane for $4 \mathrm{~h}$ and then harvested them for qRT-PCR, ELISA, and western blot analysis for HIF-1 $\alpha$, VEGF, and HO- 1 expression at different time points up to $24 \mathrm{~h}$. Untreated cells and those exposed to $1.0 \mathrm{mM}$ DMOG (Cayman Chemicals, Ann Arbor, MI) for $4 \mathrm{~h}$ served as negative or positive controls respectively. To explore the effect of isoflurane preconditioning on hypoxic conditions, HUVECs were divided into CON (normoxia), Hypoxia (hypoxia for $4 \mathrm{~h}$ ), ISO (0.32 mM isoflurane exposure for $4 \mathrm{~h}+$ normoxia condition for $24 \mathrm{~h})$, and ISO plus Hypoxia $(0.32 \mathrm{mM}$ isoflurane exposure for $4 \mathrm{~h}+$ normoxia condition for $24 \mathrm{~h}+$ hypoxia for $4 \mathrm{~h}$ ) groups. Hypoxic condition was made by continuous supplement of humidified $95 \% \mathrm{~N}_{2} / 5 \% \mathrm{CO}_{2}$ in a tightly closed chamber. These cells were then collected to assess the expression of HIF-1 $\alpha$.

To further elucidate the signaling pathways that mediate the effects of isoflurane preconditioning on HIF-1 $\alpha$ expression, we incubated HUVECs with or without the phosphatidylinositol 3-kinase (PI3K) inhibitors LY 294002 at $50 \mu \mathrm{M}$ or wortmannin at $5 \mu \mathrm{M}$, and mammalian target of rapamycin (mTOR) inhibitor rapamycin at $5 \mu \mathrm{M}$ and glycogen synthase kinase $3 \beta$ (GSK $3 \beta$ ) inhibitor SB 216763 at $10 \mu \mathrm{M}$ for 30 min prior to $0.32 \mathrm{mM}$ isoflurane exposure for $4 \mathrm{~h}$. These inhibitors were all purchased from Cell Signaling Technology (Danvers, MA). Twenty-four hours later, the cells were harvested for western blot analysis for total or phospho-Akt (Ser 473), total or phospho-mTOR (Ser 2448), total or phospho-GSK $3 \beta$ (Ser 9) and HIF-1 $\alpha$ expressions. The downstream molecules of mTOR, phosphorylation of 4E-BP1 (Ser 65) and P70 $0^{\text {s6k }}$ (Thr 389) [22], were also investigated. Furthermore, to clarify if the HIF-1 $\alpha$ protein stability is regulated by isoflurane pre-treatment, protein half-life study was performed as described previously [23, 24]. HUVECs were cultured in $1.0 \mathrm{mM}$ DMOG, $5 \mathrm{ng} / \mathrm{ml}$ TGF- $\beta 1,0.32 \mathrm{mM}$ isoflurane or normoxia condition for $4 \mathrm{~h}$. The DMOG, TGF- $\beta 1$ and normoxia condition served as positive or negative controls, respectively. Following exposure, $5 \mu \mathrm{M}$ cycloheximide (CHX) (Sigma, St. Louis, MO) was added to cell cultures for different periods of time ranging from 15 to $45 \mathrm{~min}$. The relative HIF- $1 \alpha$ protein level at time zero was defined as $100 \%$. To determine whether isoflurane exposure inhibited PHD2 expression, we performed a western blot analysis of PHD2 protein in HUVECs.

Finally, to evaluate the effect of isoflurane preconditioning on skin tissue flap survival and the potential role of HIF- $1 \alpha$, we randomly divided 40 rats into five groups ( 8 rats per group). Group 1 rats were subjected to a standard random-pattern skin flap surgery without any treatments served as the negative control (CON); Group 2, 3, and 4 animals were administrated with PBS, scrambled siRNA or HIF$1 \alpha$ siRNA respectively for $48 \mathrm{~h}$ and exposed to isoflurane preconditioning followed by the random-pattern skin flap surgery (ISO, Neg-siR, and HIF-siR); Group 5 rats received DMOG treatment, served as a positive control (DMOG). These animals received intraperitoneal administration of DMOG at a dosage of $40 \mathrm{mg} / \mathrm{kg}$ body weight $48 \mathrm{~h}$ before the surgical procedure, at the time of the surgery and $24 \mathrm{~h}$ after surgery [8]. Rats were anesthetized for skin flap survival, full-field laser perfusion imager (FLPI) measurements (at 7 day postoperatively) and for microvessel density evaluation (at 10 day post-operation).

\section{HIF-1 $\alpha$ siRNA and gene transfection}

GV115-GFP-lentivirus carrying a small hairpin RNA (shRNA) targeting the rat HIF-1 $\alpha$ gene or negative control sequence was constructed by Shanghai FudanBio Technology Co., Ltd. (Shanghai, China). HIF-1 $\alpha$ siRNA sequences were 5'-GCCTCTTCGACAAGCTTAA-3' and the scrambled siRNA sequences were 
5'-AGCGACTGTGCCAATTCCATT-3'. To generate the lentivirus, the recombinant vector and packaged plasmids (psPAX2 and pMD) were co-transfected into $293 \mathrm{~T}$ cells. The final titer of recombinant virus was 1 $\times 10^{9} \mathrm{TU} / \mathrm{ml}$. The lentivirus were injected into the subdermal layer spanning the whole area of the mapped skin flap for $48 \mathrm{~h}$ prior to the onset of experimental procedures (a total of 12 injection points on the flap, 50 $\mu \mathrm{l}$ each point, total $600 \mu \mathrm{l})$.

\section{Preparation of random-pattern skin flaps}

After an overnight fast, animals were first anesthetized by an intraperitoneal injection of $40-50 \mathrm{mg} / \mathrm{kg}$ sodium pentobarbital. Adequate anesthesia depth was confirmed by pinch flexion/withdrawal test. Under aseptic conditions, a random-pattern, caudally based dorsal skin flap $(2.5 \times 10 \mathrm{~cm})$ was elevated from the rats and resutured after a silicon sheet was placed between the flap and wound bed. No axial vessels were incorporated into the flap in which the ischemic gradient is proportional to the distance from the base.

\section{Flap survival evaluation}

The skin flap survival was evaluated by a digital image analysis. The necrotic area (defined by dark color and scar formation) and total flap areas were delineated and surface areas were calculated using Image-Pro Plus Software (version 6.0, Media Cybernetics Inc., Bethesda, MD) by an investigator who was blinded to the experimental groups. The skin flap survival results were expressed as percentages of the survival area relative to the total surface area of the flap.

\section{Full-field laser perfusion imager (FLPI)}

FLPI were measured under anesthesia using The Moor instrument (Axminster, UK) as described previously [25]. Briefly, the FLPI measurements were performed in a warm and quiet environment. The CCD camera was placed $30 \mathrm{~cm}$ above the back of each rat. Settings for low-resolution/high-speed images included a display rate of $25 \mathrm{~Hz}$, time constant of $1.0 \mathrm{~s}$, and camera exposure time of $20 \mathrm{~ms}$, with values expressed in blood perfusion unit (BPU). The contrast images were processed to display a color-coded live flux image (red: high perfusion, blue: low perfusion).

\section{Enzyme-Linked Immunosorbent Assay (ELISA)}

VEGF levels were measured using Quantikine human enzyme-linked immunosorbent assay (ELISA) kits from R\&D Systems (Minneapolis, MN) by strictly adhering to the manufacturer's instructions. Levels of VEGF protein in cell culture supernatants were expressed in $\mathrm{pg} / \mathrm{ml}$.

\section{Real-time RT-PCR}

Total RNA was isolated from cells or skin flap tissues using the Trizol reagent (Invitrogen, Carlsbad, CA) and RNeasy kit (Qiagen, Düsseldorf, Germany). These RNA samples were then reverse transcribed into single-stranded cDNA by using the first-strand cDNA synthesis kit (Promega, Madison, WI). These cDNA products were further amplified using qPCR by SYBR Green RT-PCR kit (Bioteke, Beijing, China). Sequencespecific primers are listed in Table 1. The PCR cycles were as follows: $95^{\circ} \mathrm{C}$ for $3 \mathrm{~min}$ and then 39 cycles of $95^{\circ} \mathrm{C}$ for $10 \mathrm{~s}, 55^{\circ} \mathrm{C}$ for $1 \mathrm{~min}, 72^{\circ} \mathrm{C}$ for $45 \mathrm{~s}$ and a final $65^{\circ} \mathrm{C}$ for $5 \mathrm{~min}$. Relative expression of qPCR products was determined by the Delta-Delta CT method to normalize with GAPDH mRNA expression.

\section{Protein extraction and Western blot}

Total cellular protein was extracted from rat tissues or cultured cells by using a RIPA lysis buffer (Beyotime, Jiangsu, China) containing $50 \mathrm{mM}$ Tris- $\mathrm{HCl}$ (pH 7.4), $150 \mathrm{mM} \mathrm{NaCl}, 1 \%$ Triton X-100, 1\% sodium deoxycholate, $0.1 \%$ SDS, $1 \mathrm{mM}$ EDTA, $1 \mathrm{mg} / \mathrm{ml}$ leupeptin, $2.5 \mathrm{mM}$ sodium orthovanadate and $1 \mathrm{mg} /$ $\mathrm{ml}$ aprotinin. Western blot analysis was then performed as described previously [11, 12]. Briefly, 30-80 $\mu \mathrm{g}$ of protein samples were loaded onto a $10 \%$ SDS gel, and after electrophoresis, were transferred onto nitrocellulose membranes. The primary antibodies against HIF- $1 \alpha$ (Novus Biologicals, Littleton, CO), VEGF (Abcam, Cambridge, UK), HO-1 (Abcam), and PHD2 (Novus Biologicals) were used. The primary antibodies against total and phospho-Akt (Ser 473), total and phospho-mTOR (Ser 2448), total and phospho-GSK3 $\beta$ (Ser 9), total and phospho-4E-BP1 (Ser 65), total and phospho-P70 ${ }^{\text {skk }}$ (Thr 389) were purchased from Cell Signaling Technology. Immunoreactivity signal was visualized by Tanon gel imaging systems (Shanghai, China) and analyzed by Image-Pro Plus Software. 
Sun/Li/Zhang/Hu/Jiang: Isoflurane Improves Skin Flap Survival

Table 1. Primer sequences used for quantitative RT-PCR

\begin{tabular}{clcc}
\hline Gene name & \multicolumn{1}{c}{ Primer sequence } & $\begin{array}{c}\text { Product length } \\
\text { (bp) }\end{array}$ & Tm $\left({ }^{\circ} \mathrm{C}\right)$ \\
\hline \multirow{2}{*}{ Human HO-1 } & 5'-AAGACTGCGTTCCTGCTCAAC-3'; & 247 & 61.1 \\
& 5'-AAAGCCCTACAGCAACTGTCG-3'; & & 60.9 \\
Human VEGF & 5'-AGGGCAGAATCATCACGAAGT-3'; & 175 & 58.7 \\
& 5'-AGGGTCTCGATTGGATGGCA-3'; & & 60.9 \\
Human GAPDH & 5'-CTGGGCTACACTGAGCACC-3'; & \multirow{2}{*}{101} & 60.1 \\
& 5'-AAGTGGTCGTTGAGGGCAATG-3'; & & 61.1 \\
Rat HIF-1 $\alpha$ & 5'-ACCGTGCCCCTACTATGTCG-3'; & \multirow{2}{*}{121} & 59.9 \\
& 5'-GAGCCACCAGTGTCCAAAAC-3'; & & 58.7 \\
Rat VEGF & 5'-CCTGGCTTTACTGCTGTACCT-3' & \multirow{2}{*}{164} & 61.4 \\
& 5'-GCTGGTAGACGTCCATGAACT-3' & & 61.8 \\
Rat GAPDH & 5'-GACGCTTTGGTGAAGAAACTGA-3' & \multirow{2}{*}{104} & 57.5 \\
& 5'-CACACGGCAATAAATGACATGAG-3' & & 58.8 \\
\hline
\end{tabular}

Evaluation of microvessel density in tissue samples

To evaluate microvessel density, we first stained tissue samples with the endothelial cell marker von Willebrand Factor [25, 26]. In brief, rats were anesthetized and full thickness skin flap specimens measuring $0.5 \mathrm{~cm} \times 0.5 \mathrm{~cm}$ from proximal margin $3 \mathrm{~cm}$ from the base were harvested, fixed in $10 \%$ saline-buffered formalin, embedded in paraffin, and cut into 5 - $\mu \mathrm{m}$-thick sections. We then stained these sections with a rat monoclonal anti-von Willebrand Factor antibody (DAKO, Denmark). Microvessel density was assessed by measuring the number of von Willebrand Factor-positive microvessels in 5 fields of each immunohistochemistry slide $(\times 100)$. All evaluation of microvessel density was conducted by two investigators who were blinded to the identification of tissue groups.

\section{Statistical analysis}

Data are expressed as mean \pm SD. One-way analysis of variance (ANOVA) followed by post hoc Newman-Keuls Multiple Comparison Test was used for statistical analysis. Data were analyzed using Prism 5 for Windows software (GraphPad Software, Inc, San Diego, CA). A $p$ value less than 0.05 was considered statistically significant.

\section{Results}

Isoflurane exposure induced expression of $H I F-1 \alpha, V E G F$ and $H O-1$ in vitro

In this study, we first exposed HUVECs to isoflurane for modification of different gene expressions. Our data showed that the levels of HIF- $1 \alpha$ protein exhibited a marked increase $4 \mathrm{~h}$ after isoflurane treatment $(0.34 \pm 0.02$ vs. $0.18 \pm 0.01, p<0.05)$ and increased further at $12 \mathrm{~h}$ and $24 \mathrm{~h}(0.89 \pm 0.09,0.92 \pm 0.11$ vs. $0.18 \pm 0.01, p<0.01)$ compared to the control cells (Fig.1A). Moreover, the expression of HO-1 and VEGF proteins was also induced by approximately 3 fold $(0.78 \pm 0.09 v s .0 .26 \pm 0.01, p<0.01)$ and 2.5 fold (507 $\pm 19 v s .196 \pm 19$, $p<0.01$ ), respectively, $24 \mathrm{~h}$ after isoflurane exposure compared to the control cells (Fig.1A $\& \mathrm{~F})$. The mRNA levels of these two genes were also similar following isoflurane exposure (Fig.1D). Similar observations were also made in human skin fibroblast cells (Fig.1, B, E \& F).

HIF-1 $\alpha$ expression was analysed using western blot in HUVECs $24 \mathrm{~h}$ after preconditioning with $0.16,0.32$ and $0.48 \mathrm{mM}$ isoflurane for $4 \mathrm{~h}$. Our data showed that both 0.32 and 0.48 $\mathrm{mM}$ isoflurane treatment induced the HUVECs to express HIF-1 $\alpha$ protein compared to $0.16 \mathrm{mM}$ group $(0.42 \pm 0.06,0.47 \pm 0.08$ vs. $0.26 \pm 0.04, p<0.05)$. However, there was no significant difference between 0.32 and $0.48 \mathrm{mM}$ groups (Fig.1C). Thus, the concentration of $0.32 \mathrm{mM}$ (1.0 MAC) was used in the following experiments. To understand the impact of isoflurane preconditioning against hypoxic injury, we determined the effects of isoflurane preconditioning on expression of HIF-1 $\alpha$ in hypoxic condition. The data shows that incubation of HUVECs in the hypoxia condition or isoflurane alone for $4 \mathrm{~h}$ induced the levels of HIF- $1 \alpha$ protein significantly and that a further accumulation was noted in ISO plus Hypoxia group (Fig. 1G). 


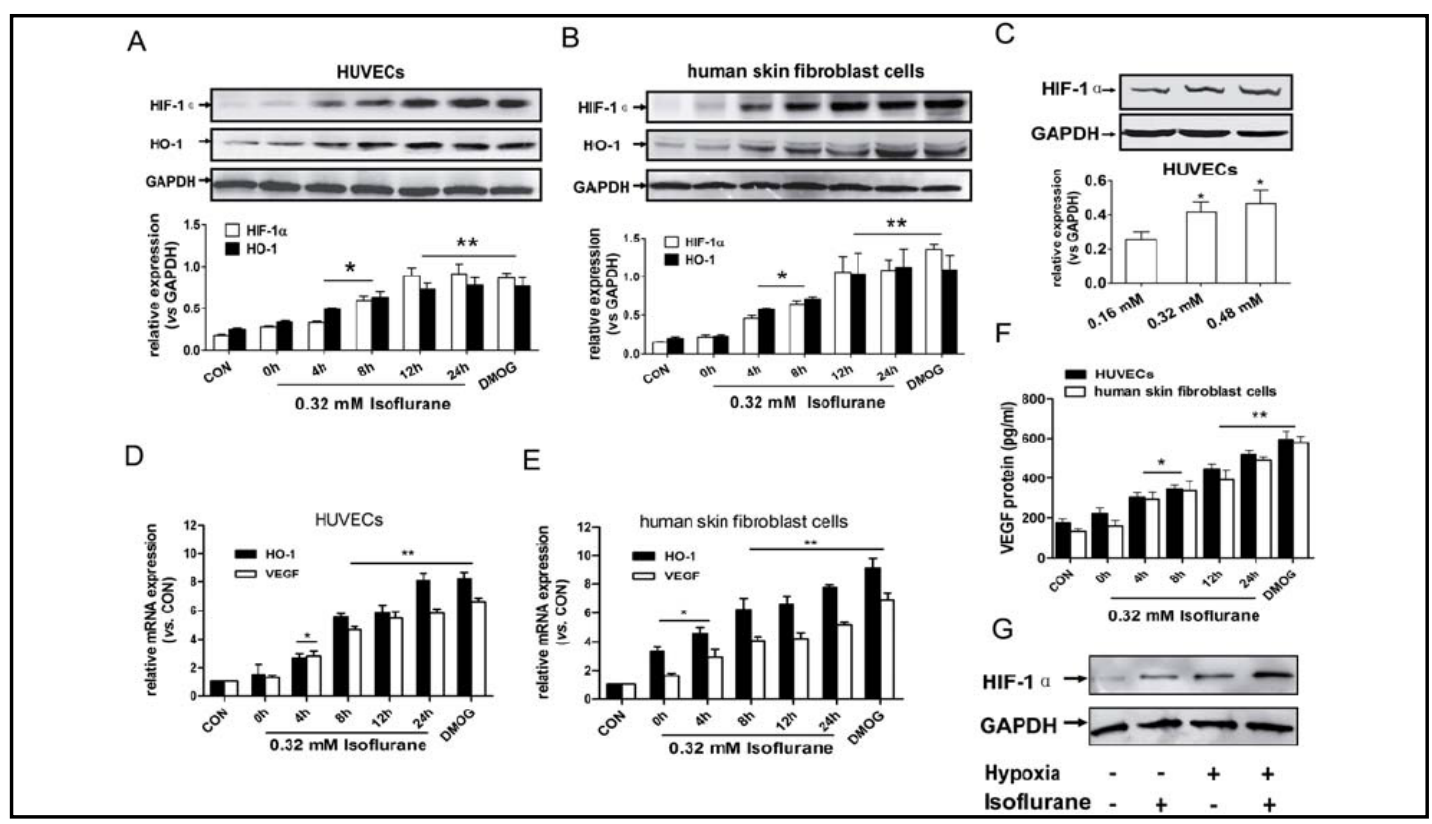

Fig. 1. Isoflurane exposure induced expression of HIF-1 $\alpha$, VEGF and HO-1 in vitro. (A \& B) Both HUVECs and human skin fibroblast cells were exposed to isoflurane for $4 \mathrm{~h}$ and were analyzed up to $24 \mathrm{~h}$ post isoflurane exposure. Compared to the control cells (CON), levels of HIF-1 $\alpha$ and HO- 1 proteins exhibited a marked increase after isoflurane treatment. (C) Isoflurane exposure induced a dose-dependent increase in HIF-1 $\alpha$ expression in HUVECs. (D, E) Compared to the control cells (CON), levels of HO-1 and VEGF mRNA were also obviously induced after isoflurane exposure. (F) Compared to the control cells (CON), isoflurane exposure significantly increased levels of VEGF protein in both cell culture conditioned media. (G) Incubation with hypoxia condition or isoflurane alone induced the levels of the HIF- $1 \alpha$ protein significantly. A further accumulation was noted in isoflurane plus hypoxia. ${ }^{*} P<0.05$ and ${ }^{* *} P<0.01$ compared to the CON or to 0.16 $\mathrm{mM}$ isoflurane exposure.

Fig. 2. Isoflurane exposure activated Akt-mTOR and Akt-GSK $3 \beta$ pathway and increased HIF-1 $\alpha$ expression. (A) Cultured HUVECs were pre-treated with LY 294002 or wortmannin and then exposed to isoflurane. Western blot analysis shows that both LY 294002 and wortmannin inhibited isoflurane-induced increases in p-Akt (Ser 473), p-mTOR (Ser 2448), p-GSK $3 \beta$ (Ser 9) and HIF-1 $\alpha$. (B) Cultured HUVECs were pre-treated with SB 216763 and then exposed to isoflurane. Western blot analysis shows that SB 216763 pre-treatment could further increase isoflurane-induced p-GSK $3 \beta$

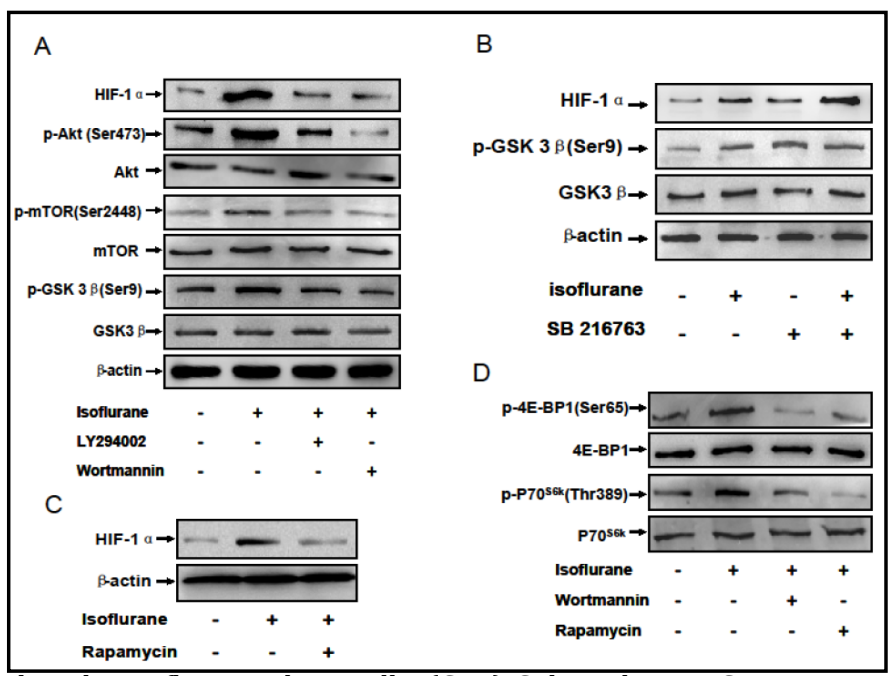
(Ser 9) and HIF-1 $\alpha$ expression compared to the isoflurane-alone cells. (C, D) Cultured HUVECs were pretreated with wortmannin or rapamycin then exposed to isoflurane. Western blot analysis shows that both wortmannin and rapamycin inhibited isoflurane-induced p-4E-BP1 (Ser 65) and p-P70 s6k (Thr 389) and HIF-1 $\alpha$ expression.

Isoflurane activates Akt-mTOR and Akt-GSK $3 \beta$ pathway to increase HIF-1 $\alpha$ expression

To determine the underlying molecular events by which isoflurane induced HIF- $1 \alpha$ expression, we studied the Akt-mTOR and Akt-GSK $3 \beta$ pathway. We found that HUVECs 

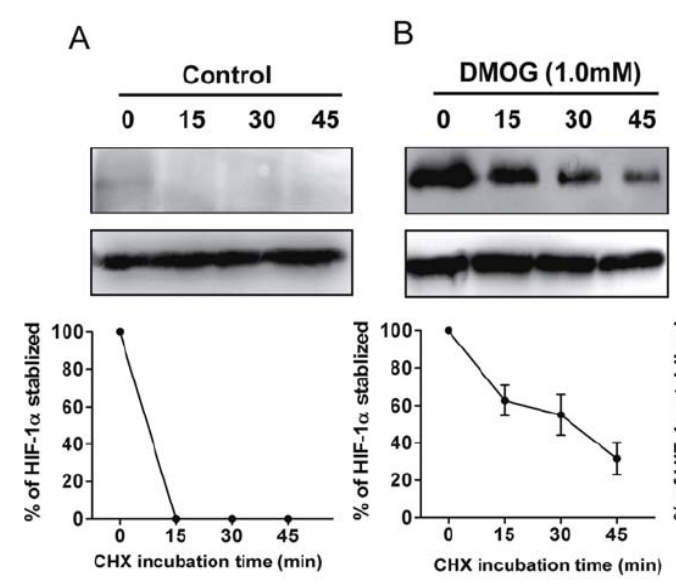

C

\begin{tabular}{llll}
\hline 0 & 15 & 30 & 45 \\
\hline & & &
\end{tabular}
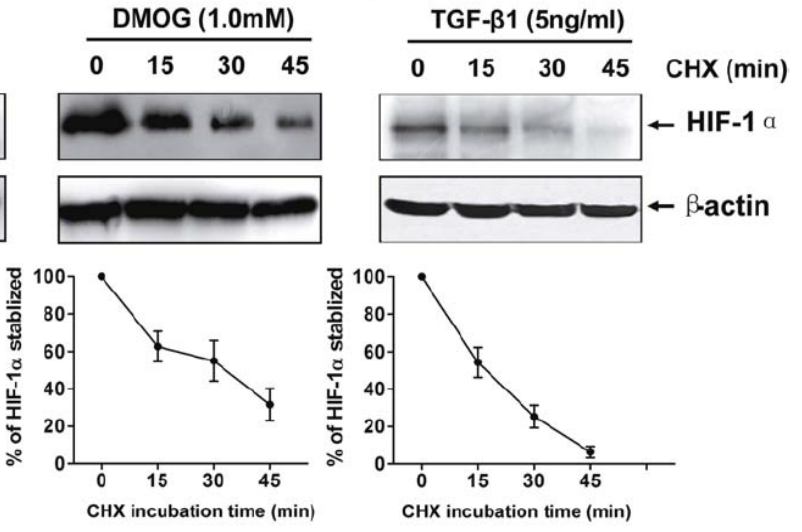

D

isoflurane $(0.32 \mathrm{mM})$

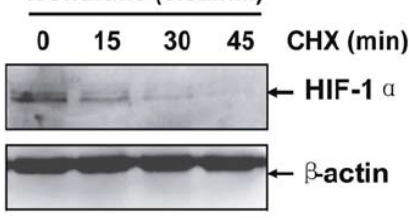

$\mathrm{E}$
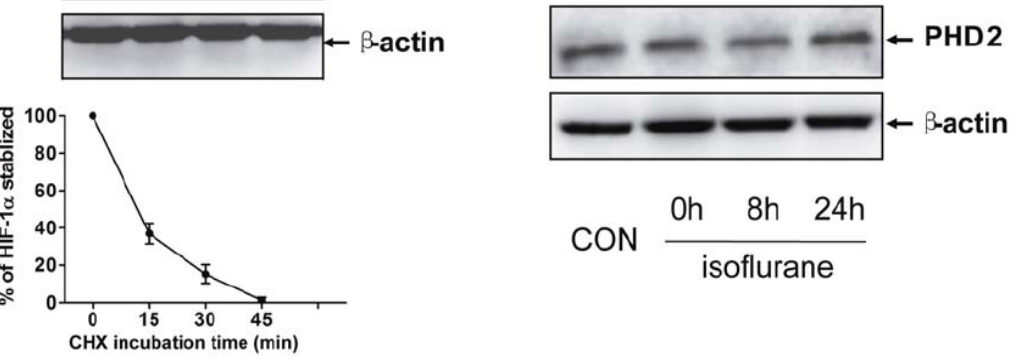

$$
\operatorname{CON} \frac{\text { Oh } 8 \mathrm{~h} 24 \mathrm{~h}}{\text { isoflurane }}
$$

Fig. 3. Isoflurane increased HIF- $1 \alpha$ protein stability in HUVECs. HUVECs were cultured in normoxic condition (A) with $1.0 \mathrm{mM}$ DMOG (B), $5 \mathrm{ng} / \mathrm{ml} \mathrm{TGF}-1 \beta$ (C), or $0.32 \mathrm{mM}$ isoflurane (D) for $4 \mathrm{~h}$. Following exposure, $5 \mu \mathrm{M}$ cycloheximide ( $\mathrm{CHX}$ ) was added to cell cultures for time periods ranging from 15 to $45 \mathrm{~min}$. The relative HIF-1 $\alpha$ protein level at time zero was defined as $100 \%$. HUVECs were treated with $0.32 \mathrm{mM}$ isoflurane for $4 \mathrm{~h}$ and then harvested for western blot analysis of PHD2 expression at different time points (E).

exposed to isoflurane-induced expression of phospho-Akt (Ser 473), phospho-mTOR (Ser 2448) and phospho-GSK $3 \beta$ (Ser 9) (Fig. 2A). In addition to the blockade of activation of Akt, mTOR and GSK $3 \beta$ proteins, LY 294002 and wortmannin significantly inhibited isofluraneinduced expression of HIF-1 $\alpha$ protein (Fig. 2A). Likewise, rapamycin, an inhibitor of mTOR kinase activity, attenuated the induction of $4 \mathrm{E}-\mathrm{BP} 1$ and $\mathrm{P} 70^{\mathrm{sk \textrm {k }}}$ phosphorylation and HIF-1 $\alpha$ expression induced by isoflurane treatment (Fig. 2C \& D). On the other hand, expression of phospho-GSK $3 \beta$ (Ser 9) and HIF-1 $\alpha$ proteins induced by isoflurane exposure could be enhanced further by SB 216763 (Fig.2B). These data demonstrates that both Akt-mTOR and Akt-GSK3 $\beta$ signaling pathways were involved in HIF-1 $\alpha$ activation induced by isoflurane exposure.

\section{Isoflurane increased HIF-1 $\alpha$ protein stability}

A recent study showed non-hypoxic stimulation [such as transforming growth factor $\beta 1$ (TGF-1 $\beta$ )] was able to stabilize HIF-1 $\alpha$ protein $[23,24]$. Therefore, we assessed whether isoflurane can induce HIF- $1 \alpha$ protein stability. Our data showed that the half-life of HIF$1 \alpha$ protein was up to $15 \mathrm{~min}$ in TGF-1 $\beta$-stimulated cells and up to $12 \mathrm{~min}$ in isofluranetreated cells after addition of CHX to block on-going protein synthesis; however, normoxic control cells showed only $\sim 5$ min of HIF- $1 \alpha$ protein (Fig. 3A, C \&D). In addition, exposure to 
Fig. 4. Effects of HIF-1 $\alpha$ knockdown on regulation of HIF- $1 \alpha$ and VEGF expression in vivo. $\mathrm{PBS}$, scrambled siRNA (NegsiR) or HIF-1 $\alpha$ siRNA (HIF-siR) was injected into subdermal layer of rat skin and $48 \mathrm{~h}$ later, the rats were treated with or without $1.5 \%$ isoflurane for $4 \mathrm{~h}$. Twenty-four hours later, the skin flaps were taken for analyses. (A) Intracellular fluorescence signals in skin flaps were evaluated for transfection

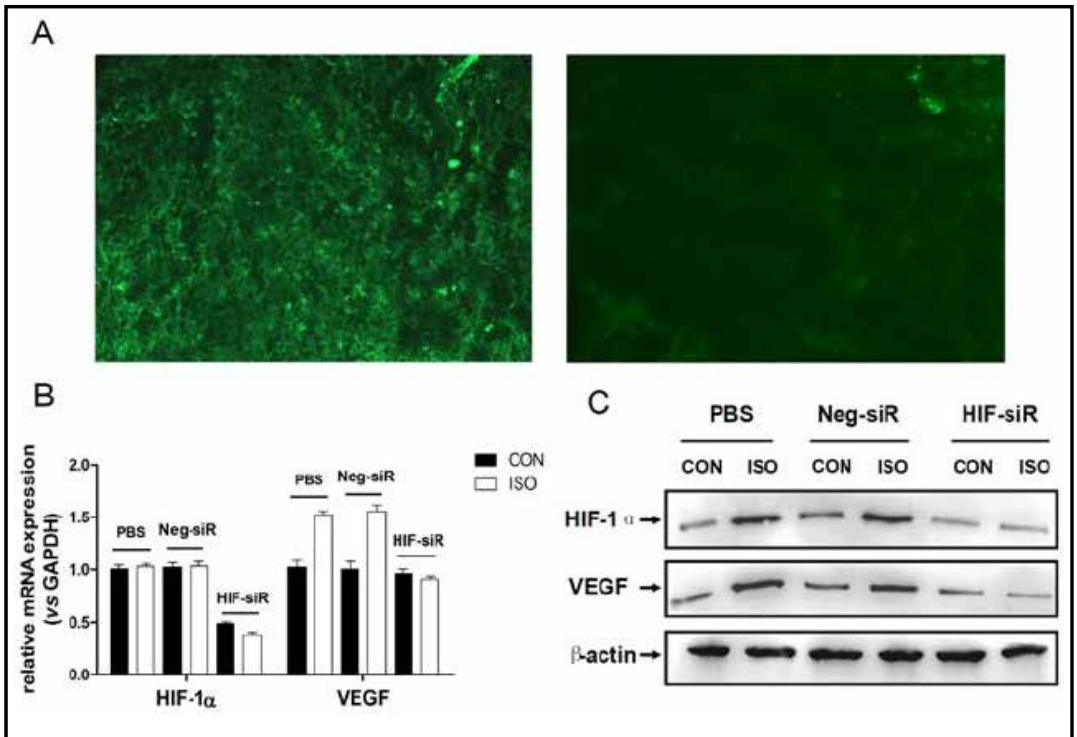
efficiency in animals injected with HIF-1 $\alpha$ siRNA as shown in the left panel. Skin flaps from animals injected with PBS is shown in the right panel. (B) Tissues from skin flap were subjected to qRT-PCR analyses. The levels of HIF-1 $\alpha$ mRNA did not obviously change after isoflurane preconditioning in PBS and Neg-siR groups. In HIF-siR group, the HIF- $1 \alpha$ mRNA levels decreased significantly. Expression of VEGF mRNA was induced by isoflurane preconditioning but blocked by HIF-1 $\alpha$ siRNA transfection compared to PBS or scrambled siRNA plus isoflurane-treated animals. (C) Tissues from skin flap were subjected to western blot. Expression of HIF-1 $\alpha$ and VEGF protein was induced by isoflurane preconditioning but blocked by HIF- $1 \alpha$ siRNA transfection compared with PBS or scrambled siRNA plus isoflurane-treated animals.

isoflurane did not alter the levels of PHD2 expression (Fig. 3E). These results indicate that the increased expression of HIF- $1 \alpha$ following isoflurane exposure could be at least due to isoflurane-induced the stabilization of HIF- $1 \alpha$ protein in a PHD-independent manner.

The effect of HIF-1 $\alpha$ knockdown on regulating expression of HIF-1 $\alpha$ and its downstream genes in vivo

The effect of HIF- $1 \alpha$ knockdown on regulating expression of HIF- $1 \alpha$ and its downstream genes in vivo was investigated. Our data exhibited intracellular green fluorescence in skin flap specimens from the animals, $48 \mathrm{~h}$ after GFP-labeled siRNA-related lentivirus subdermal layer injection, whereas no such fluorescence was found in the skin flaps of PBS-injected control animals (Fig.4A). The rats with and without HIF- $1 \alpha$ knockdown were treated with $1.5 \%$ isoflurane for $4 \mathrm{~h}$. Twenty-four hours later, dorsal skin flap specimens were harvested for qRT-PCR and western blot analysis. The knockdown efficiency of HIF- $1 \alpha$ siRNA was confirmed by a significant decrease in the expression of HIF- $1 \alpha$ and its target gene, VEGF (Fig.4B \& C). In addition, qRT-PCR data showed that isoflurane preconditioning in PBS and Neg-siR groups didn't significantly change expression of HIF-1 $\alpha$ mRNA (Fig.4B), indicating that isoflurane preconditioning modulates HIF- $1 \alpha$ via a posttranscriptional pathway, similar to the findings from our previous study $[11,12]$.

HIF-1 $\alpha$ knockdown abrogated isoflurane preconditioning-improved skin flap survival

As regularly observed, necrosis was seen consistently in the distal region of the flap from all animal experiments. In this study, we took digital photographs on postoperative day 7 and found that the characteristic distribution of necrosis and the visible differences between the each group (Fig.5A). Quantitative data showed a higher survival rate of the tissue flaps in the ISO, Neg-siR and DMOG group compared to the negative control rats (56.7 $\pm 6.7 \%, 55.2 \pm 6.5 \% 62.5 \pm 6.0 \%$ vs. $48.5 \pm 5.6 \%, p<0.05$ or $p<0.01)$. However, knockdown 
Fig. 5. HIF-1 $\alpha$ knockdown abolished isoflurane preconditioning-improved skin flap survival. Forty rats were randomly divided into five groups, i.e., Control (CON), PBS plus isoflurane treatment (ISO), scramble siRNA plus isoflurane treatment (Neg-siR), HIF$1 \alpha$ siRNA plus isoflurane treatment (HIF-siR), and dimethyloxallylglycine treatment (DMOG) groups. After random-pattern skin flap operations, rats were anesthetized for flap survival evaluation and for full-field laser perfusion imager (FLPI) evaluation on postoperative day 7. (A) Comparative photographs of rats in five groups showing the characteristic difference in flap necrosis (above) and FLPI (below). (B) Quantitative data on the survival rate of the flaps in various groups. ${ }^{*} p<0.05$ and ${ }^{* *} p<0.01$ compared with CON. \#p $<0.05$ compared with ISO.

Fig. 6. Microvessel density in flaps. A, Ten days after operation, the tissue flaps were stained with anti-von Willebrand Factor antibody and microvessel density was evaluated under a microscope (red arrows) $(\times 100)$ and summarized. B, Statistical analysis of microvesssel counts in different groups. Enhanced vascularization existed in the ISO, the Neg-siR and the DMOG group ( $\mathrm{n}=6,{ }^{*} p<0.05$ compared with CON. \#p<0.05 compared with ISO).
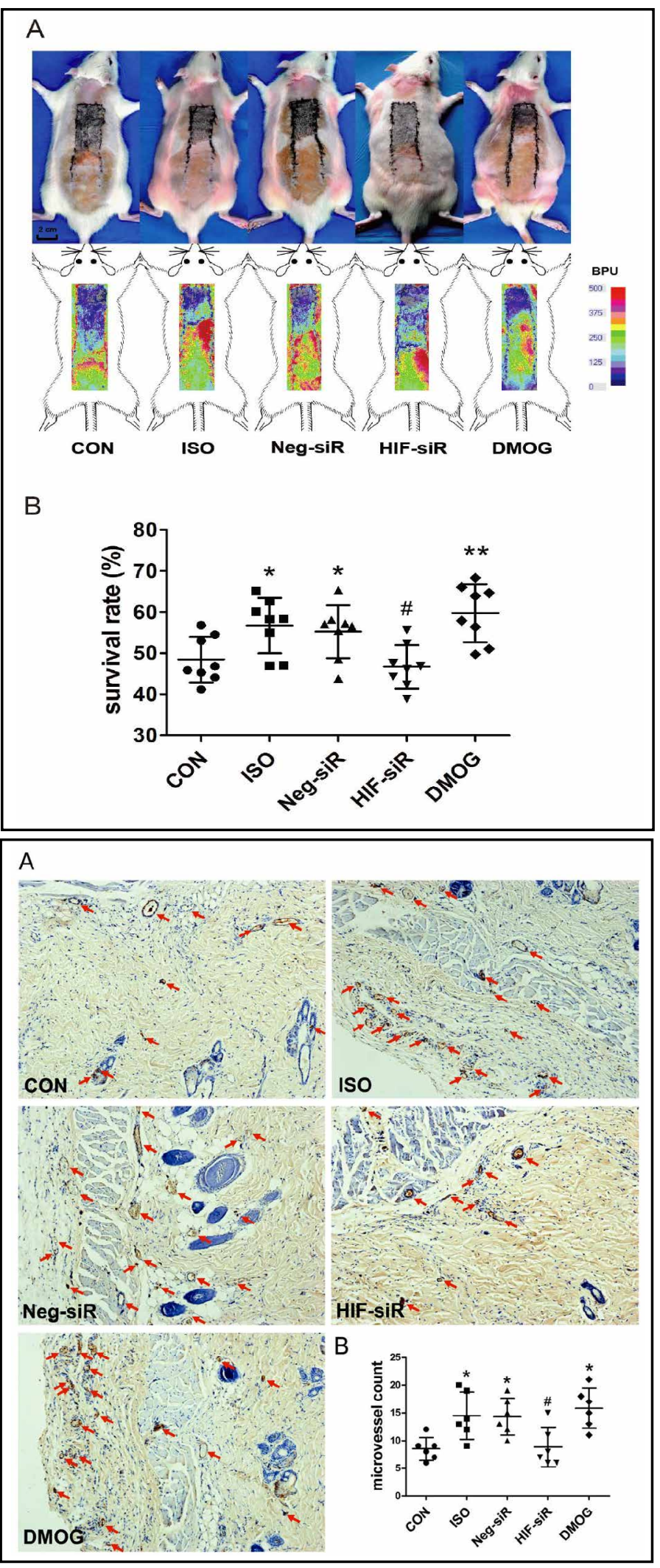

of HIF- $1 \alpha$ expression using HIF- $1 \alpha$ siRNA blocked such improved survival $(46.7 \pm 5.3 \%$ of HIF-siR vs. $56.7 \pm 6.7 \%$ of ISO, $p<0.05$ ) (Fig.5B). 
At 10 days after operation, we found that isoflurane and DMOG treatment tended to result in a significant increase in microvessel count compared to CON group (14.5 \pm $4.3,15.8 \pm 3.6$ vs. $8.5 \pm 2.1, p<0.05$ ). Knockdown of HIF- $1 \alpha$ expression also attenuated isoflurane preconditioning induced improvement of vascularity $(8.8 \pm 3.5$ vs. $14.5 \pm 4.3$, $p<0.05$ ) (Fig. 6A \& B).

\section{Discussion}

In this study, we investigated the effects of isoflurane in improving the survival of random-pattern skin flaps in rat and the molecular mechanisms underlying this process. Results from the present study confirmed our hypothesis that isoflurane preconditioning protects skin flap against ischemic necrosis in a rat model. The major findings were: 1). Isoflurane preconditioning improved survival of the random-pattern skin flap in rat model; 2). Under normoxic conditions, isoflurane preconditioning with clinically relevant doses induces expression of HIF- $1 \alpha$ protein and subsequently VEGF and HO-1 expression; and 3). Isoflurane-induced HIF- $1 \alpha$ expression was mediated by activation of the Akt-mTOR and AktGSK $3 \beta$ signaling pathways. Further studies are necessary to evaluate the clinical significance of isoflurane-improved survival of the random-pattern skin flap.

Previous studies, including ours, have confirmed that isoflurane treatment was able to induce expression of HIF-1 $\alpha$ in neurons [12], myocardium [13], renal [14], and protected these organs from ischemic injury. Thus, in this study, we extend the previous findings by showing a similar protective effect in the skin flap tissues. Vascular endothelial cells are the lining component for all vascular networks, and are sensitive to ischemia [27, 28]. HUVECs are regarded as a standard endothelial cell line for analysis of vasoreactive responses to various conditions $[8,28]$. In addition, skin fibroblasts comprise a large percentage of the cellular portion of the skin [29]. To confirm the human relevance of the findings, HUVECs and human skin fibroblast cells were chosen as the representative cell lines for in vitro study. Our in vitro data clearly demonstrated that isoflurane treatment induced HIF-1 $\alpha$ expression. Most importantly, our in vivo study showed that isoflurane preconditioning significantly increased HIF-1 $\alpha$ levels in rat skin flap tissues and reduced ischemia-induced skin flap necrosis. However, this protective effect was attenuated by knockdown of HIF-1 $\alpha$ expression using HIF- $1 \alpha$ siRNA, suggesting that isoflurane-protective effect is regulated by HIF- $1 \alpha$.

Moreover, the defined molecular mechanisms by which isoflurane induces HIF- $1 \alpha$ is not fully understood. Levels of HIF-1 $\alpha$ protein are determined by the balance between protein synthesis and degradation [30]. In line with a previous study [13], our data confirmed that activation of the Akt-mTOR pathway played a role in isoflurane-induced HIF-1 $\alpha$ expression and mTOR activated P70 ${ }^{\mathrm{s} 6 \mathrm{~K}}$ and 4E-BP1 [22] to control the translation of HIF- $1 \alpha$ mRNA. In addition, GSK $3 \beta$ is another downstream substrate of Akt and may promote HIF- $1 \alpha$ stabilization and expression [31,32]. These data led us to studying the role of Akt-GSK $3 \beta$ in the regulation of HIF- $1 \alpha$ protein after isoflurane treatment. Our in vitro data also showed that treatment of HUVECs with isoflurane increased the levels of phospho-Akt and GSK $3 \beta$ and therefore induced HIF- $1 \alpha$ expression. Such an induction of HIF- $1 \alpha$ and phospho-GSK $3 \beta$ expression could be blocked by LY 294002 and wortmannin. In addition, inhibiting GSK $3 \beta$ activity with SB 216763 could further increase isoflurane-induced phospho-GSK $3 \beta$ and HIF-1 $\alpha$ expression compared to the isoflurane-alone cells. These data clearly suggest that isoflurane-induced HIF-1 $\alpha$ expression was also mediated or at least in part by activation of the Akt-GSK $3 \beta$ gene pathway. Activated Akt will phosphorylate GSK $3 \beta$ protein and decrease GSK $3 \beta$ kinase activity and in turn increases HIF- $1 \alpha$ levels. In comparison of the half-life of HIF-1 $\alpha$ protein in the cells stimulated by isoflurane and normoxic control, the data showed that isoflurane significantly increased HIF- $1 \alpha$ protein stability. Under normoxia condition, PHD2 is the critical oxygen sensor controlling the low steady-state levels of HIF-1 $\alpha$ [33] and decreased PHD2 activity could result in HIF-1 $\alpha$ stabilization. In this study, however, exposure to isoflurane did not inhibit PHD2 expression, suggesting that isoflurane-induced 
HIF- $1 \alpha$ stabilization was independent to PHD. It is likely that GSK $3 \beta$ negatively regulated HIF- $1 \alpha$ by initiating HIF- $1 \alpha$ phosphorylation and promoting proteasomal degradation [32], although further study is needed to clarify it.

$\mathrm{HO}$ is a ubiquitous enzyme that catalyses the breakdown of heme to equimolar amount of biliverdin, carbon monoxide and ferrous iron. Among the three mammalian isoforms of $\mathrm{HO}$, only the HO-1 is inducible. Activation of HO-1 has been shown to minimize the damage after ischemia followed by reperfusion in a number of organ systems including the skin flap tissues $[6,18,34,35]$. VEGF is one of the most important growth factors involved in vasculogenesis and angiogenesis. Acute hypoxia will induce expression of HO-1 and VEGF, which is transcriptionally mediated by HIF- $1 \alpha$ activation $[15,36]$. On this basis, these two HIF-1 $\alpha$ target genes can modulate microcirculatory properties and can therefore play a role to induce the survival of random-pattern skin flaps. Using anti-von Willebrand factor staining to visualize microvessels in tissues, we observed the number of von Willebrand Factor positive microvessels was higher in the ISO group compared with CON group, suggesting that increased expression by isoflurane preconditioning cooperates with hypoxic stabilization and accumulation of HIF- $1 \alpha$ which ensures enhanced expression of the HIF- $1 \alpha$ target genes, such as HO-1 and VEGF, and up-regulates vascularity.

Our current study also has some potential limitations. For example, HIF- $1 \alpha$ is a powerful transcription factor with hundreds of down-stream genes. In this study, we just demonstrated induction of VEGF and HO-1 expression. Other genes may also have participated in isoflurane-induced survival of the random-pattern skin flap, e.g., isoflurane preconditioning was able to induce erythropoietin (EPO) expression [14], which is also capable to prevent musculocutaneous tissue from ischemic necrosis [37]. In addition, bone marrow-derived cells including hematopoietic stem cells, mesenchymal stem cells, endothelial progenitor cells and their generations improve wound healing by mobilization, differentiation and angiogenesis [38-40]. These processes require the local environment to generate appropriate chemotactic signals and progenitor cells to respond appropriately through signaling pathways such as stromal cell derived factor-1 (SDF-1)-CXCR4 [41] and VEGF-VEGF receptor 2 [39]. Chang et al. confirmed that DFO promoted ischemic flap survival through increased endothelial progenitor cells mobilization via increased HIF- $1 \alpha$ and SDF$1 \alpha$ levels, which could be reversed by age-related HIF-1 $\alpha$ down regulation [9]. Recently, Takaku et al. demonstrated that DMOG activated the HIF-1 $\alpha$ not only in ischemic area but also in bone marrow cells, thereby enhanced the recruitment of progenitor cells from bone marrow to the ischemic part of flap to reconstitute the vasculature [7]. From these points of view, bone marrow-derived cells may play an essential role in promoting ischemic skin flap survival. While the question of whether isoflurane preconditioning can induce bone marrow-derived progenitor cells mobilization, differentiation and homing should be tested in future in vivo experiments. Even though isoflurane preconditioning may not be superior to DMOG administration, our current data may still have significant clinical perspectives. This is due to the fact that isoflurane is a safe inhalation anaesthetic and has been widely used in plastic and reconstructive surgery for many years. Isoflurane preconditioning is non-invasive, easily applicable and cost-effective. Thus, we expect that it will be of clinical significance to use isoflurane for surgical procedures with the random-pattern skin flaps.

In summary, our study provides evidence that isoflurane preconditioning at a clinically relevant concentration, $24 \mathrm{~h}$ before ischemic assault can improve survival of the random-pattern skin flaps. This protective effect seems to be mediated through increase in expression of HIF- $1 \alpha$ protein, perhaps via Akt-mTOR and Akt-GSK3 $\beta$ signaling pathways. In our previous study [12], we showed that induction of HIF- $1 \alpha$ was due to extracellular signal-related kinases (ERK), while in the current manuscript, we found Akt-GSK $3 \beta$ and AktmTOR in mediating HIF- $1 \alpha$ induction, indicating that it is multiple factorial regulations of HIF-1 $\alpha$ expression. Moreover, both Akt and ERK genes are part of the RAS signaling pathway. However, in our future study, we will perform experiments to investigate which gene(s) is most important in isoflurane regulation of HIF-1 $\alpha$ expression in skin flap tissues. 
Sun/Li/Zhang/Hu/Jiang: Isoflurane Improves Skin Flap Survival

\section{Acknowledgements}

This research is supported in part by National Natural Science Foundation of China (No.81201021) and a grant from the Shanghai Jiao Tong University, School of Medicine (No.11XJ21026).

\section{References}

$>1 \quad$ Kerrigan C: Skin flap failure: pathophysiology. Plast Reconstr Surg 1983;72:766-777.

2 Wang GL, Jiang BH, Rue EA, Semenza GL: Hypoxia inducible factor 1 is a basic-helix-loop-helix-PAS heterodimer regulated by cellular $\mathrm{O}_{2}$ tension. Proc Natl Acad Sci U S A 1995;92:5510-5514.

-3 Semenza GL: Hydroxylation of HIF-1: oxygen sensing at the molecular level. Physiology (Bethesda) 2004;19:176-182.

4 Akhavani MA, Sivakumar B, Paleolog EM, Kang N: Angiogenesis and plastic surgery. J Plast Reconstr Aesthet Surg 2008;61:1425-1437.

-5 Yancopoulos GD, Davis S, Gale NW, Rudge JS, Wiegand SJ, Holash J: Vascular-specific growth factors and blood vessel formation. Nature 2000;407:242-248.

-6 Harder Y, Amon M, Schramm R, Rücker M, Scheuer C, Pittet B, Erni D, Menger MD: Ischemia-induced up-regulation of heme oxygenase-1 protects from apoptotic cell death and tissue necrosis. J Surg Res 2008;150:293-303.

7 Takaku M, Tomita S, Kurobe H, Kihira Y, Morimoto A, Higashida M, Ikeda Y, Ushiyama A, Hashimoto I, Nakanishi H, Tamaki T: Systemic preconditioning by a prolyl hydroxylase inhibitor promotes prevention of skin flap necrosis via HIF-1-induced bone marrow-derived cells. PLoS One 2012;7:e42964.

8 Shafighi M, Olariu R, Fathi AR, Djafarzadeh S, Jakob SM, Banic A, Constantinescu MA: Dimethyloxalylglycine stabilizes HIF- $1 \alpha$ in cultured human endothelial cells and increases random-pattern skin flap survival in vivo. Plast Reconstr Surg 2011;128:415-422.

-9 Chang EI, Loh SA, Ceradini DJ, Chang EI, Lin SE, Bastidas N, Aarabi S, Chan DA, Freedman ML, Giaccia AJ, Gurtner GC: Age decreases endothelial progenitor cell recruitment through decreases in hypoxia-inducible factor 1alpha stabilization during ischemia. Circulation 2007;116:2818-2829.

10 Weng R, Li Q Li H, Yang M, Sheng L: Mimic hypoxia improves angiogenesis in ischaemic random flaps. J Plast Reconstr Aesthet Surg 2010;63:2152-2159.

11 Li QF, Wang XR, Yang YW, Su DS: Up-regulation of hypoxia inducible factor-1alpha by isoflurane in Hep3B cells. Anesthesiology 2006;105:1211-1219.

12 Li QF, Zhu YS, Jiang H: Isoflurane preconditioning activates HIF-1 alpha, iNOS and Erk1/2 and protects against oxygen-glucose deprivation neuronal injury. Brain Res 2008;15:26-35.

13 Raphael J, Zuo Z, Abedat S, Beeri R, Gozal Y: Isoflurane preconditioning decreases myocardial infarction in rabbits via up-regulation of hypoxia inducible factor 1 that is mediated by mammalian target of rapamycin. Anesthesiology 2008;108:415-425.

14 Zhang L, Huang H, Chen J, Liu J, Zhao H, Vizcaychipi MP, Ma D: Pre-treatment with isoflurane ameliorates renal ischemic-reperfusion injury in mice. Life Sci 2011;88:1102-1107.

-15 Wang C, Weihrauch D, Schwabe DA, Bienengraeber M, Warltier DC, Kersten JR, Pratt PF Jr, Pagel PS: Extracellular signal-regulated kinases trigger isoflurane preconditioning concomitant with upregulation of hypoxia-inducible factor-1alpha and vascular endothelial growth factor expression in rats. Anesth Analg 2006;103:281-288.

16 Lee MC, Chen CH, Kuo MC, Kang PL, Lo A, Liu K: Isoflurane preconditioning-induced cardio-protection in patients undergoing coronary artery bypass grafting. Eur J Anaesthesiol 2006;23:841-847.

17 Haroun-Bizri S, Khoury SS, Chehab IR, Kassas CM, Baraka A: Does isoflurane optimize myocardial protection during cardiopulmonary bypass? J Cardiothorac Vasc Anesth 2001;15:418-421.

18 Lv X, Yang L, Tao K, Liu Y, Yang T, Chen G, Yu W, Lv H, Wu F: Isoflurane preconditioning at clinically relevant doses induce protective effects of heme oxygenase- 1 on hepatic ischemia reperfusion in rats. BMC Gastroenterol 2011;11:31.

19 Dirnagl U, Becker K, Meisel A: Preconditioning and tolerance against cerebral ischaemia:from experimental strategies to clinical use. Lancet Neurol 2009;8:398-412. 


\section{Cellular Physiology Cell Physiol Biochem 2013;31:579-591 and Biochemistry \\ Sun/Li/Zhang/Hu/Jiang: Isoflurane Improves Skin Flap Survival}

20 Jiang H, Huang Y, Xu H, Sun Y, Han N, Li QF: Hypoxia inducible factor- $1 \alpha$ is involved in the neurodegeneration induced by isoflurane in the brain of neonatal rats. J Neurochem 2012;120:453-460.

21 Wang Q, Liang G, Yang H, Wang S, Eckenhoff MF, Wei H: The common inhaled anesthetic isoflurane increases aggregation of huntingtin and alters calcium homeostasis in a cell model of Huntington's disease. Toxicol Appl Pharmacol 2011;250:291-298.

22 Hara K, Yonezawa K, Kozlowski MT, Sugimoto T, Andrabi K, Weng QP, Kasuga M, Nishimoto I, Avruch J: Regulation of eIF-4E BP1 phosphorylation by mTOR. J Biol Chem 1997;272:26457-26463.

23 McMahon S, Charbonneau M, Grandmont S, Richard DE, Dubois CM: Transforming growth factor beta1 induces hypoxia-inducible factor-1 stabilization through selective inhibition of PHD2 expression. J Biol Chem 2006;281:24171-24181.

24 Watanabe T, Yasue A, Tanaka E: Inhibition of transforming growth factor $\beta 1$ (TGF- $\beta 1$ )/ Smad3 signaling decreases hypoxia-inducible factor $1 \alpha$ (HIF-1 $\alpha$ ) protein stability by inducing prolyl hydroxylase 2 (PHD2) expression in human periodontal ligament cells. J Periodontol 2012: doi:10.1902/jop.2012.120373.

25 Du Z, Zan T, Li H, Li Q: A study of blood flow dynamics in flap delay using the full-field laser perfusion imager. Microvasc Res 2011;82:284-290.

26 Yang M, Li Q Sheng L, Li H, Weng R, Zan T: Bone marrow-derived mesenchymal stem cells transplantation accelerates tissue expansion by promoting skin regeneration during expansion. Ann Surg 2011;253:202209.

27 Signorelli S, Jennings P, Leonard MO, Pfaller W: Differential effects of hypoxic stress in alveolar epithelial cells and microvascular endothelial cells. Cell Physiol Biochem 2010;25:135-144.

28 Henderson PW, Singh SP, Belkin D, Nagineni V, Weinstein AL, Weissich J, Spector JA: Hydrogen sulfide protects against ischemia-reperfusion injury in an in vitro model of cutaneous tissue transplantation. J Surg Res 2010;159:451-455.

-29 Raffetto JD: Dermal pathology, cellular biology, and inflammation in chronic venous disease. Thromb Res 2009;123:S66-S71.

30 Yee Koh M, Spivak-Kroizman TR, Powis G: HIF-1 regulation: not so easy come, easy go. Trends Biochem Sci 2008;33:526-534.

31 Mottet D, Dumont V, Deccache Y, Demazy C, Ninane N, Raes M, Michiels C: Regulation of hypoxia-inducible factor-1alpha protein level during hypoxic conditions by the phosphatidylinositol 3-kinase/Akt/glycogen synthase kinase 3beta pathway in HepG2 cells. J Biol Chem 2003;278:31277-31285.

-32 Flügel D, Görlach A, Michiels C, Kietzmann T: Glycogen synthase kinase 3 phosphorylates hypoxia-inducible factor $1 \alpha$ and mediates its destabilization in a VHL-independent manner. Mol Cell Biol 2007;27:3253-3265.

33 Berra E, Benizri E, Ginouvès A, Volmat V, Roux D, Pouysségur J: HIF prolyl-hydroxylase 2 is the key oxygen sensor setting low steady-state levels of HIF-1alpha in normoxia. EMBO J 2003;22:4082-4090.

34 Berne JP, Lauzier B, Rochette L, Vergely C: Carbon monoxide protects against ischemia-reperfusion injury in vitro via antioxidant properties. Cell Physiol Biochem 2012:29;475-484.

-35 Tsuchihashi S, Fondevila C, Kupiec-Weglinski JW: Heme oxygenase system in ischemia and reperfusion injury. Ann Transplant 2004;9:84-87.

-36 Lee PJ, Jiang BH, Chin BY, Iyer NV, Alam J, Semenza GL, Choi AMK: Hypoxia-inducible factor-1 mediates transcriptional activation of the heme oxygenase- 1 gene in response to hypoxia. J Biol Chem 1997;272:5375-5381.

-37 Rezaeian F, Wettstein R, Egger JF, Sandmann F, Rücker M, Tobalem M, Vollmar B, Menger MD, Harder Y: Erythropoietin-induced upregulation of endothelial nitric oxide synthase but not vascular endothelial growth factor prevents musculocutaneous tissue from ischemic damage. Lab Invest 2010;90:40-51.

38 Guo S, Cheng Y, Ma Y, Yang X: Endothelial progenitor cells derived from CD34+ cells form cooperative vascular networks. Cell Physiol Biochem 2010;26:679-688.

-39 Tepper OM, Capla JM, Galiano RD, Ceradini DJ, Callaghan MJ, Kleinman ME, Gurtner GC: Adult vasculogenesis occurs through in situ recruitment, proliferation, and tubulization of circulating bone marrow-derived cells. Blood 2005;105:1068-1077.

40 Wu YJ, Chen LW, Scott PG, Tredget EE: Mesenchymal stem cells enhance wound healing through differentiation and angiogenesis. Stem Cells 2007;25:2648-2659.

-41 Ceradini DJ, Kulkarni AR, Callaghan MJ, Tepper OM, Bastidas N, Kleinman ME, Capla JM, Galiano RD, Levine JP, Gurtner GC: Progenitor cell trafficking is regulated by hypoxic gradients through HIF-1 induction of SDF1. Nat Med 2004;10:858-864. 